\title{
Unable to conform, unwilling to rebel? Youth, culture, and motivation in globalizing Japan
}

\author{
Tuukka Toivonen ${ }^{1}$, Vinai Norasakkunkit ${ }^{2 *}$ and Yukiko Uchida ${ }^{3}$ \\ 1 Green Templeton College, University of Oxford, Oxford, UK \\ 2 Psychology Department, Minnesota State University Mankato, Mankato, MN, USA \\ ${ }^{3}$ Kokoro Research Center, Kyoto University, Kyoto, Japan
}

\section{Edited by:}

Heejung Kim, University of California

Santa Barbara, USA

Reviewed by:

Beth Morling, University of Delaware, USA

Takeshi Hamamura, Chinese

University of Hong Kong, Hong Kong

*Correspondence:

Vinai Norasakkunkit, 23 Armstrong Hall, Minnesota State University,

Mankato, MN 56001, USA.

e-mail: vinai.norasakkunkit@mnsu.edu
This paper investigates the effects of globalization on Japanese young adults from sociological and psychological perspectives. While Japan's socio-economic institutions have shown mainly resistant (or "hot") reactions to globalization, individual-level adaptations remain oriented toward conformity to dominant life expectations, which remain largely unchanged, despite decreasing rewards. However, a socially withdrawn sub-group (the so-called hikikomori) appears to be unable to conform yet is also unwilling to rebel. The experimental evidence we review suggests such youth deviate from typical Japanese motivational patterns but have not necessarily become more Western. This poses serious problems in an interdependence-oriented culture, but the paralysis of this group seems to be an outcome of labor market change rather than a psychopathology. Finally, we also identify a contrasting group - whom we call the quiet mavericks - that adapts in creative and integrative (or "cool") ways by negotiating conformist pressures tactfully. Our account sheds light on just how complex and painful the psychological and sociological effects of globalization can be for young people in conformist societies, with implications to policy and social sustainability.

Keywords: globalization, youth, motivation, marginalization, post-industrialization, Japan, NEET, hikikomori
The American anthropologist Clifford Geertz famously argued that the Western conception of the person as "a bounded, unique, more or less integrated motivational, and cognitive universe," clearly set apart from other individuals as well as social context, is a "rather peculiar idea in the context of the world's cultures" (Geertz, 1984, p. 126). A recent review of relevant cross-cultural psychological studies has empirically verified the specificity of this disembedded idea of the person (Henrich et al., 2010). However, few psychologically oriented studies have examined what happens when this peculiar but dominant idea is imposed on a non-Western society through globalization-related processes. Do we find stark resistance to such cultural change on the societal and individual levels, or can we detect convergence with the West (see Chiu and Cheng, 2007)? How do dominant motivations and behaviors begin to shift?

To address these broad questions, this article investigates in detail the consequences of globalization to youth in Japan. Globalization, while a multi-layered phenomenon often associated with greater global interconnectedness, is used here mainly to refer to the pressures that promote a shift toward de-regulated, flexible labor markets. This is a structural shift with intimate links to the "global values" of consumerism, individualism, competition, and efficiency (Pilkington and Johnson, 2003). We focus on youth not only due to the difficulty of examining a larger demographic slice of the population, but because it can reasonably be expected that, lacking labor market experience and related resources, young adults in their 20s are likely to feel the pressures of globalization more directly and acutely than many other age-groups ${ }^{1}$. While not its main objective, this paper is therefore relevant to understanding the contours of "emerging adulthood" (Arnett, 2004) in Japan in relation to the sphere of work especially. The specific puzzle we pursue is: how are Japanese youth adapting their motivational processes and behaviors amid contradictory cultural and socio-economic pressures?

We have chosen to investigate Japan because, while economically similar to western countries, it represents a prototypical "conformist" society. To avoid confusion, conformism as an attribute of a given society implies, drawing on Mertonian sociological thinking related to the concept of anomie (Merton, 1949), the inseparability of culturally defined, dominant success goals, and culturally approved institutional means. In a conformist society, therefore, acquiescence to respected protocols, roles, and institutionalized life paths tends to be so important that "success" does not exist independent of such legitimate means, at least for those who subscribe to mainstream values. Cultural psychological studies have shown that, in conformist environments, social structures and practices motivate individuals to adjust the self to the situation (as opposed to influencing it); maintain social harmony (instead of disrupting it by standing out); and to affirm one's interdependence with others (rather than asserting one's

\footnotetext{
${ }^{1}$ Immigrants as well as the broader issues of international mobility and social inclusion are clearly part of globalization too, but our focus on youth in the homogeneous context of mainstream Japan leads us to discuss such issues only tangentially.
} 


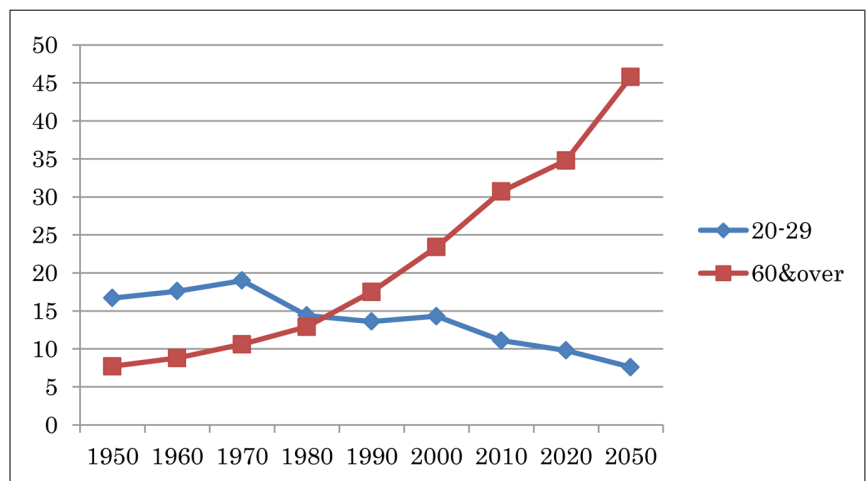

FIGURE 1 | The share of 20- to 29-year-olds and those aged 60 and above relative to Japan's total population (1950-2010, with projections for 2020 and 2050). Sources: Statistics Bureau (http://www.stat.go.jp/data/ jinsui/2.htm) and Japan Aging Research Center (http://www.jarc.net/aging/ jp/06feb/060203JARC_Population.pdf). Accessed on January 20, 2011.

independence; see Markus and Kitayama, 1991; Kitayama and Uchida, 2003). It is easy to see from here that the potential for tension between Japanese cultural tendencies and the abovementioned "global values" is enormous. Though certain qualifications need to be made, Japan remains a conformist society par excellence where, due central cultural features as well as the coincidence of seniority-based hierarchies (Nakane, 1970) and accelerating demographic aging (see Figure 1), conformist pressures remain strong, especially in the labor market sphere. All this makes Japan a particularly interesting - and challenging - context for studying the impacts of US-led globalization on young people.

To unravel the impacts of globalization on young people's motivational processes and behaviors, this account investigates (1) Japan's responses to globalization on an institutional regulatory level, with a focus on the youth labor markets; (2) dominant individual-level adaptations to globalization in a changed labor market environment; and (3) the responses of distinctive groups of youth. On a theoretical level, we interpret our findings with reference to Cheng and Chiu's (2010) model of psychological reactions to globalization. In their scheme, "emotional, reflexive responses evoked by perceived threats to the integrity of one's heritage cultural identity" are conceptualized as "hot" reactions (Cheng and Chiu, 2010, p. 8). They typically lead to xenophobic behaviors that attack and try to quarantine offensive elements, including "global values" as mentioned above. On the other hand, "cool" reactions, while not equivalent to an uncritical espousal of global (predominantly western) influences, denote "reflective mental processes that facilitate the use of ideas from foreign cultures as means to further one's valued goals" (Cheng and Chiu, 2010, p. 11)2. When reacting "coolly," individuals (and the institutions they steer) utilize foreign cultural

\footnotetext{
${ }^{2}$ This formulation of "cool" reactions has close affinities with Inglehart's "postmaterialist values" (see Inglehart and Welzel, 2005) and with the values of Florida's "creative class" (Florida, 2002), both of which emphasize the tolerance of diversity and openness to new ideas.
}

inputs as intellectual resources to promote their own culturally specific goals, yielding syntheses. Put differently, compared to resistant hot reactions, cool reactions are selectively integrative of old and new elements. What Cheng and Chiu's model pays less attention to is the possible avoidance of explicit reactions altogether, which we find is in some cases relevant. In any case, one sub-text of their theory seems to be that hot reactions lead to tensions and even national or individual decline, while cool approaches facilitate more "successful" adaptations to globalization. It is therefore of great significance to understand the dynamics and consequences of hot vs. cool reactions in different societies.

Taking into account the above, our sociological and psychological data suggests the following: First, Japan's youth labor market institutions have responded to globalization in a predominantly "hot" fashion as conservative elites have resisted reforming the core of the employment system - still a central cultural symbol. Second, young labor market entrants have borne the brunt of resulting burdens, with a growing group ("ritualists"; see below) conforming to dominant social expectations but without enjoying expected rewards. Another more withdrawn group ("retreatists") suffers deeper isolation partly due to distinctive psychologies that deviate from both typical Japanese and western motivational patterns. Our findings challenge existing research on such so-called hikikomori (as withdrawn youth are now called in Japan and internationally) by showing that this phenomenon is to be understood neither in terms of a psychopathology, essentialized notions of Japanese culture nor resistance to those with individualistic values, but as a product of social change interacting with psychological processes. Third, there indeed is a general tendency among Japanese people toward avoidance motivations, but this does not mean active non-conformism is entirely absent: we also identify an emerging layer of youth ("quiet mavericks") who possess the cultural and social agility to utilize global influences without being defeated by conformist pressures. Most analysts of Japan, building on western assumptions, have tended to ignore all but the loudest forms of resistance (e.g., demonstrations, movements, and explicitly rebellike individuals), and the most controversial media-driven youth problems (see Goodman et al., 2011). Incidentally however, it may be precisely this less visible, quieter stratum that most effectively renegotiates seemingly contradictory cultural pressures in the Japanese context, so exemplifying "cool" reactions to globalization.

\section{LABOR MARKET INSTITUTIONS: "HOT" REACTIONS}

We begin by considering how and to what extent the Japanese youth labor markets have been modified in the face of globalization in the 1990s and 2000s. Globalization's effects on young people's motivational processes must be approached in this way, for they are never direct but proceed through various institutional "filters" (Mills and Blossfeld, 2005, p. 6). One would expect the labor markets, when reformed after Western models, to be a key conduit for the transmission of values such as competitiveness and individualism.

As opposed to the so-called liberal market economies (LMEs) characterized by labor markets that are lightly regulated and of which the US is a prime example - Japan has been identified as a coordinated market economy (CME; Hall and Gingerich, 
2009). Such CMEs are said to feature stronger labor market regulations and institutionalized wage-bargaining procedures, one consequence of which is lower labor mobility and the strong protection of status-based advantages. CMEs have frequently been viewed as inflexible, resistant to reform and highly challenged by American-style globalization and post-industrialization. While somewhat different to CMEs such as Germany and Finland in terms of relationship of the state and private firms, Japan has shared many of these features: for instance, it has been nearly impossible, in a both legal and normative sense, for employers to lay off core workers. At the same time, a large buffer of marginal workers - comprising housewives as well as male day-laborers has long co-existed in Japan with the protected core. How did these institutions react when globalization pressures, including the perceived necessity to cut labor costs amid low growth, hit them with full force in the 1990s? ${ }^{3}$

The best way to sum up the response of Japan to globalization pressures is to say that its labor markets were reformed significantly but in a covertly asymmetric fashion: Japan's senior government and business elites of the older generation resisted pressures for change by protecting the classic long-term employment system a central cultural symbol - by confining reforms to an expanding peripheral labor force dominated by new entrants into the labor market, thereby blocking much of the potential that youth have to offer to innovative ideas and strategies that can contribute to increased competitiveness in the global marketplace (see Weathers, 2001; Gottfried, 2008, p. 189; Genda, 2005) ${ }^{4}$. In terms of Cheng and Chiu's conceptualization, this amounts to a "hot" reaction to globalization. Non-standard employment such as short-term contract work proliferated in tandem with rising levels of education (Kariya, 2011) as Japan further de-industrialized and shed relatively stable manufacturing jobs in the 1990s and 2000s (Rebick, 2005). This has had detrimental consequences to many youth in the context of a one-shot recruitment system where those not hired immediately upon graduation from high school or university are very rarely allowed to enter the core workforce at a later stage (Kosugi, 2008).

By contrast, in the US the labor markets are de-regulated and kept flexible throughout so that all workers are to some extent dismissable, which is advantageous to companies when they need to reduce labor costs or shed workers who are no longer required by them. In Japan, the continued cultural centrality of the long-term employment system has led to an increasingly divided situation where those who fail to enter it are generally considered inferior in terms of status - as if they were contaminants to be kept in the margins so as to not taint a system that is itself pure. It is primarily

\footnotetext{
${ }^{3}$ Japan experienced a major real estate bubble up to 1991, the burst of which ushered in a decade-long recession that saw the country's GDP growth rate sink from 3.4\% in 1991 to $-2 \%$ in 1998, after which growth recovered only modestly. This recession generated enormous pressures to rapidly reform the Japanese economy.

${ }^{4}$ The total share of non-standard workers (hiseiki-shain) leapt from just $20 \%$ in 1990 to $34 \%$ in 2010 (Statistics Bureau, 2011) - a nearly 60\% increase. For 15- to 24-year-olds, there was an even greater increase from 21 to $46 \%$ (of which a third were working while in education), though many more out-of-school females (36\%) than males $(26 \%)$ found themselves in this category. For 25- to 34-year-old women, the rates were even higher at $41 \%$ working non-standard jobs in 2010 compared to only $14 \%$ of males.
}

this de-regulated section of the labor force that has been called to espouse new values by being more "self-directed" (shutaiteki) and "self-responsible" (jikosekinin wo motsu), whereas protected core workers are generally expected to conform to entrenched cultural codes (though mobility has risen here too). Sadly for the younger group, genuine alternative paths to economic autonomy, and social security - including support toward entrepreneurial activity - have remained extremely limited. The next section considers the implications this situation has had for young people's behaviors and motivational processes.

\section{DOMINANT INDIVIDUAL-LEVEL ADAPTATIONS}

While Japan's central labor market institutions strongly resisted globalization pressures in the 1990s and 2000s, young people have been forced to function within a reformed institutional landscape. The key dilemma herein has been that, even as labor markets have grown significantly less secure, general cultural attitudes and social security policies have continued to strongly favor those in permanent long-term employment, to which various financial and status-related benefits mainly accrue. The dominant life-course ideal still consists of a steady progression from an excellent high school and tertiary institution into a large company, leading to rising wages that enable family formation (Chiavacci, 2008), despite the fact that fewer and fewer young labor market entrants can now hope to meet this ideal in practice ${ }^{5}$. To be sure, the Japanese public debate in the 2000s tended to suggest that the values of teenagers and 20-something had significantly changed compared to their parents' generation, moving away from hard work and company loyalty toward self-actualization or a slower pace of living. However, academic research has shown that this view has, by and large, been exaggerated and that economic stagnation and institutional dynamics far better explain young people's rapidly changing labor market behaviors (Kariya and Rosenbaum, 2003; Genda, 2005) ${ }^{6}$. Reflected in the rising popularity of striving for a career as a public servant, most (though not all) youth indeed still hold relatively conservative life-course expectations and remain security-oriented (Yamada, 2011). In a context where the state has not stepped in to compensate for the loss of labor market security and company-based welfare it remains rational for youth to seek economic security as well as adult status through competing for positions in large organizations. Indeed, a bivariate regression analysis of panel data suggests that the link between graduating from an elite university and securing a job in a large corporation is now stronger than ever (Kariya, 2011).

How have youth adapted their behaviors and motivations in this conflicting situation where socially accepted routes to

\footnotetext{
${ }^{5}$ Some important gender differences have marked these life-course expectations, with housewifery having been a major cultural goal for women up to the 1980s. Since then, women's expectations have begun to converge with males', with the majority of women wishing to combine paid work and family duties, though most still feel they have to choose between one or the other toward their late 20s and early 30s (Schoppa, 2006).

${ }^{6}$ This is not to say that value change has been completely absent or that generations do not clash over life-course goals. Brinton (2011) highlights precisely this issue when she notes that older generations' rigid ideals, accompanied by blindness to post-industrial social changes, may be one factor deepening the problems of Japanese youth.
} 


\section{Table 1 |The adaptive categories available to youth in relation to dominant cultural success goals and legitimate institutional means. (Examples from Japan marked with an asterisk).}

\begin{tabular}{|c|c|}
\hline Adaptive category & Relationship to dominant goals and means \\
\hline Ritualists & $\begin{array}{l}\text { Conform to legitimate means but have little hope for culturally expected rewards. }{ }^{*} \text { The default adaptation in conformist } \\
\text { societies. For example, those among non-standard workers (freeters) who hold middle-class expectations. }\end{array}$ \\
\hline (Quiet) mavericks & $\begin{array}{l}\text { Create original goals as well as means; engage with society on their own terms. The main group driving social change. } \\
\text { *Includes rebellion but also "quieter" and tactful forms of resistance, especially in conformist societies. For example } \\
\text { (social) entrepreneurs, activists. }\end{array}$ \\
\hline
\end{tabular}

adulthood are much harder to access? To theoretically ground our analysis, we construct a framework modeled on Merton's classic sociological typology of individual adaptations to anomie (Merton, 1938, 1949). This framework is necessarily a simplification but it allows us to expand our analytical scope beyond particular "problem youth" groups while situating such groups sociologically (which is something most studies on Japanese youth do not do systematically; see, e.g., Zielenziger, 2006). Also, it lets us set in wider context the cultural psychological findings to be reviewed later. It is important to note that we are not predominantly attempting to explain criminally deviant behavior - nor do we deny the limitations of anomie theory - but find it an effective tool for shedding light on the disjunction between culturally designated goals and legitimate institutional means that greatly affects Japanese youth at present. Although Mertonian approaches are sometimes criticized as rigidly functionalist (see Toivonen and Imoto, 2011), what we construct is an empirically grounded middle-range theory that allows for movement between distinctive social locations and that does not deny the role of agency in effecting social change.

According to Merton, in any human society, most people are "conformists" who aspire toward culturally dominant success goals through accepted institutional means (e.g., education and paid work in legitimate occupations). Meanwhile, those unable or unwilling to conform on one or both of these counts become either "innovators," "ritualists," "retreatists," or "rebels," the latter of which we have reframed as "(quiet) mavericks" for reasons to be explained (see Table 1).

Before applying this framework to Japan, two specifications are necessary. First, though most analysts would agree that the degree of social conformity is high in Japan, we assume that only those who self-identify as being part of the middle-class subscribe strongly to the dominant success goals and life-course expectations pointed out above. Approximately $90 \%$ of Japanese fulfill this condition (Cabinet Office, 2007). In this account, we focus on understanding adaptations within this majority group that can be assumed to be almost entirely ethnically Japanese. More heterogeneous and truly marginal parts of the population (e.g., ethnic minorities, the homeless, members of religious and criminal organizations, others who exist outside the confines of mainstream Japanese society) fall outside the scope of our analysis, not because they are unimportant but because the social and cultural dynamics that apply to such groups are different.

Second, the category of "innovators" makes much less sense in the context of Japanese society, since it presupposes that cultural goals and institutional means are essentially separable from each other. Members of the Japanese middle-class society possess strong expectations regarding how life-courses should unfold, with the consequence, as explained above, that any notion of success is intertwined with adherence to certain legitimate means and social roles. This stands in marked contrast to the US case where, as Merton himself surmised, innovation - the application of less recognized or even illegitimate means so as to attain economic success - is an important response in situations where the distance between dominant goals and legitimate means for reaching toward such goals seems wide. In Japan, with innovation remaining a possibility only to those not steeped in middle-class values, we posit that there is an inbuilt tendency for ritualism to be the default behavioral alternative to conformism. (The psychological reasons for this tendency will be reviewed in the next section.) For this group, abiding by acceptable behavioral norms still provides significant social rewards even as the expected economic or other benefits are foregone. This kind of a dynamic should be present in all strongly conformist societies where the economic rewards of conformity decrease while key social ideals remain the same.

Consistent with this prediction, it appears that a significant number of young people in Japan have adapted to the asymmetric labor market changes precisely through moving toward ritualism (Figure 2). In other words, they have continued to strive to conform to dominant cultural expectations despite a dramatically lower likelihood of receiving the rewards that the previous generations could expect for following the same cultural prescriptions. An expanded portion of youth undergo high education - over $50 \%$ of high school graduates now graduate 4 -year universities - but up to a fifth of even this well-educated group acquiesces to insecure, low-paid jobs ${ }^{7}$. A fourth of all 25- to 34-year-olds find themselves

\footnotetext{
${ }^{7}$ Approximately $20 \%$ of fresh university graduates could not find a stable job at the end the 2000s compared to just 7\% in 1992 (Ministry of Education, 2010).
} 


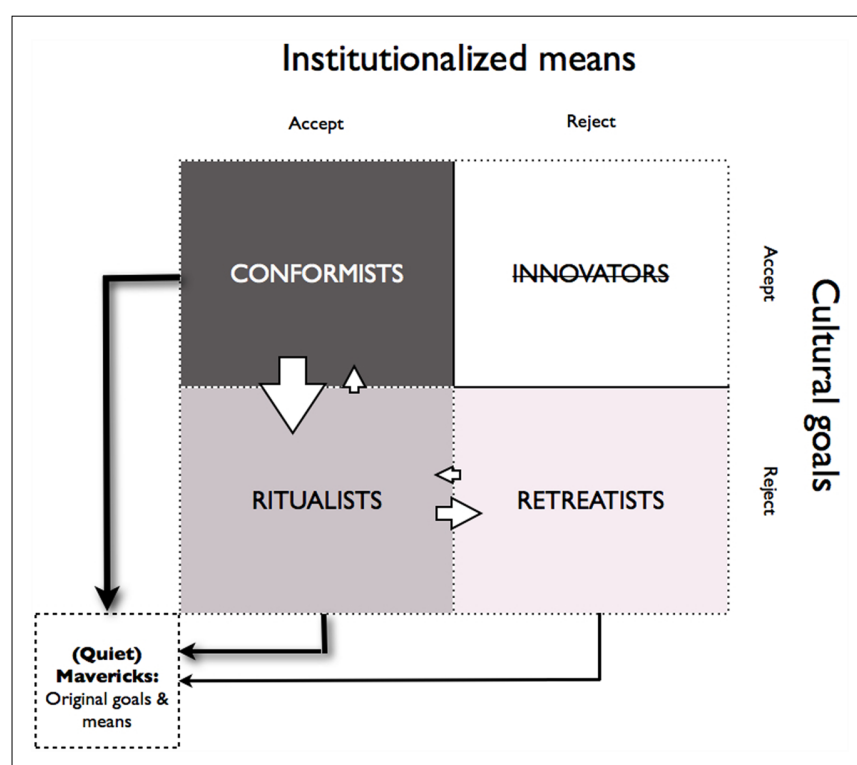

FIGURE 2 | The predicted flow of young people between adaptive categories in globalizing conformist societies such as Japan.

stuck in non-standard employment without important culturally valued rewards. Those in this group are at risk of foregoing (1) a decent income ${ }^{8}$; (2) essential occupational skills (since training takes place mainly on the job in Japan; Genda, 2005); (3) full social security benefits; (4) all-important organizational membership (see Brinton, 2011); (5) the social status of an adult fulltime worker (shakaijin; literally, "a member of society"); and (6) the opportunity to form a family ${ }^{9}$. Significant psychological distress is often suffered as a result. Puzzlingly, despite such major disadvantages, most ritualists continue to work in the (peripheral) labor force ${ }^{10}$. One reason for this is clearly that Japan's dualized labor markets make it extremely difficult to move inwards from the margins into the core labor force, resembling other CMEs like Germany and Italy in this respect. The culturally and institutionally conformist landscape further serves to keep ritualists in their place by making innovation - the deployment of alternative means while aiming for conventional life goals, for example through entrepreneurship or art - basically impossible. Despite all this, related protest movements remain surprisingly weak (though they are now possibly strengthening following recent anti-poverty rallies and the March 2011 tsunami and nuclear crises).

However, there are some youth who do move out of the labor markets altogether, whether by choice or inevitability. In journalistic and academic commentary on Japan, the phenomenon of

\footnotetext{
${ }^{8}$ According to the Cabinet Office of Japan, non-standard workers earn roughly $85 \%$ of what their standard-worker contemporaries do in the early 20 s, but only about $60 \%$ in their early 40 s.

${ }^{9}$ There are important gender differences here. Shirahase (2009) documents the significantly lower likelihood of non-standard male workers (freeters), compared to their standard-worker contemporaries, to marry and form families.

${ }^{10}$ Existing studies show that only a small minority manage to move from here into permanent positions partly because employers view prolonged non-standard employment in a starkly negative light (Kosugi, 2008).
}

social withdrawal (hikikomori) has attracted considerable attention since the early 2000s (Zielenziger, 2006; Horiguchi, 2011). In Mertonian terms, socially withdrawn youth can be positioned as retreatists who have become disillusioned with both dominant goals and legitimate means. It should be mentioned here that such youth emerged as a major social problem in Japan during rising youth unemployment: $10 \%$ of 20 - to 24 -year-olds were out of work in 2003 - double the rate of the early 1990s (Statistics Bureau, 2011). The following section proceeds to consider the motivational processes of social withdrawees by reference to original experimental data, after which we tentatively examine more actively non-conformist adaptive patterns.

\section{ATYPICAL MOTIVATIONAL PATTERNS AND AVOIDANCE BEHAVIORS}

In order to understand the peculiar situation of socially withdrawn youth in Japan, it is helpful to begin by contrasting typical Japanese psychological patterns with American ones. Previous cultural psychological studies on motivational differences (Kitayama et al., 1997; Heine et al., 1999; Morling et al., 2002) suggest that Japanese society forms an "interdependent cultural system" where individuals pay significant attention to their own shortcomings. They do so in order to improve themselves so that they can meet conformist expectations, therefore maintaining social harmony. By contrast, in an "independent cultural system" like that of the United States, individuals tend to be motivated to enhance their own self-perceived uniqueness so as to reinforce what they perceive to be positive attributes which already exist within themselves. This translates to Americans typically working harder in response to their own successes relative to their failures, while Japanese tend to work harder in response to failures relative to successes. Indeed, Heine et al. (2001) found precisely these crossculturally divergent motivational patterns in an experimental study.

Recently, Norasakkunkit and Uchida (in press) replicated Heine and colleague's study by comparing motivational patterns between Japanese university students at risk of becoming retreatists and Japanese university students likely to be conformists (low-risk group) according to their own self-reported attitudes as measured by a not in employment, education, or training ("NEET") Risk Scale developed by Uchida and Norasakkunkit (in preparation). As expected, low-risk students, much like the Japanese sample in Heine and colleagues' study, worked harder in response to receiving failure feedback relative to receiving success feedback, while this motivational pattern was reversed for high-risk students. Furthermore, Uchida and Norasakkunkit also found that high-risk students scored lower on core values of interdependence than low-risk students, suggesting that they might be "deviants" in the context of Japan's interdependent cultural system.

These findings suggest that although the motivational pattern found among high-risk Japanese students was similar to that of North American students reported in Heine and colleagues' study, a closer look at how "retreatist" tendencies were associated with motivation suggested something different. While, in contrast with the typical Japanese motivational pattern, retreatist tendencies were associated with lower motivation to work hard in the failure feedback condition, such tendencies were not necessarily 
associated with increased motivation to work hard in the success feedback condition (Norasakkunkit and Uchida, in press). In a separate survey study of actual retreatist groups ${ }^{11}$ as well as North American students and Japanese students, Uchida and Norasakkunkit (in preparation) found that the retreatist groups scored lower on both core values of interdependence and core values of independence relative to low-risk Japanese students and relative to North American students. Norasakkunkit and Uchida (in press) therefore concluded that the attitudes and motivational patterns of retreatist groups (and those at risk of becoming "NEET") represent more of a deviation from interdependence than a movement toward independence. Put another way, the deviation in attitudes and motivational patterns among the retreatist and at risk groups is more a function of being cultural dropouts (or, in the case of high-risk students, believing that one is likely to become a cultural dropout) than a function of actively embracing alternative motivational patterns or attitudes. Thus, socially and occupationally inactive youth in Japan should be understood primarily as emerging from the growing rift between culturally dominant goals and the institutional means for supporting goals such as permanent employment - in line with the sociological analysis given in the previous section - and less as a consequence of personal preference or individual psychopathology (Uchida et al., 2010).

To relate these finding to Cheng and Chiu's theory of reactions to globalization, it seems that retreatists in Japan have dissociated themselves from core cultural values of interdependence and therefore have no reason to exhibit "hot" reactions toward globalization pressures. Their reactions are instead characterized by avoidance behaviors. Moreover, since it is likely that their family expectations and educational experiences have consistently encouraged adherence to certain legitimate means and standard social roles (as discussed earlier), they probably have had very little exposure to alternative modes of agency or success. Hence, as long as they remain retreating, they may never develop an agency that is either independent or interdependent.

Next, we turn to examining more deeply how specific modes of adaptation are distributed among Japanese youth. In the preceding section we pointed out that, in the face of means-goals tensions, alongside retreatist responses (e.g., withdrawing) and ritualism, one also expects to see "acting out" behaviors such as innovative activities or organized protests. However, as existing studies in the cultural divergence of motivational processes show, modes of deviation appear to be unevenly distributed in favor of withdrawing behaviors in the Japanese cultural context. This is not necessarily surprising since earlier cultural psychological accounts have argued that the frequency of the two broad self-regulatory motivations, approach motivations, and avoidance motivations (Higgins, 1997; Elliot, 1999), tend to be unevenly distributed across cultures (Hamamura et al., 2009). "Approach motivations" are

\footnotetext{
${ }^{11}$ These comprised 28 young adults who had been socially withdrawn for 6 months or more (i.e., in regular contact with no other people except their parental families) and 433 "NEET" youth who were officially out of the labor force. Both groups were aged 15-34. See Toivonen (Forthcoming) regarding the introduction of the "NEET" category to Japan in the mid-2000s and the peculiar youth support measures that followed.
}

characterized by behaviors that are oriented toward a positive or a desirable event or possibility, such as being extroverted so as to make new friends. "Avoidance motivations," on the other hand, are characterized by behaviors that are oriented toward pre-empting an undesirable event or possibility, such as being introverted to avoid offending someone.

Hamamura and colleagues argue that the frequency of these strategies varies across cultures because what it takes to be functional and successful varies according to cultural context. In North America, for example, because high self-esteem is especially desirable and functional, the benefits of actualizing approach motivations that help to maintain high self-esteem (e.g., asserting one's positive attributes to others) outweigh the cost of potentially causing disturbance to social harmony. By contrast, in a conformist, interdependent cultural context like mainstream Japan, maintaining "face" is crucial to one's success and functionality. As it is much easier to lose face than it is to gain it, avoidance strategies (such as behaving inconspicuously) are attractive since they can effectively safeguard against the loss of face. Indeed, Hamamura and colleagues provided experimental evidence to suggest that Japanese are more attentive to avoidance-oriented information while North Americans are more attentive to approach-oriented information.

In light of this, we argue that withdrawing behavior represents an expression of avoidance motivations. Consistent with the logic explained above, withdrawing as a mode of deviance is in important respects less costly than acting out in the Japanese cultural context. This cultural psychological perspective can account for why deviant Japanese youth are more prone to "asocial" rather than "anti-social" behaviors. It does not predict the complete absence of anti-social behavior - or of democratically oriented, agentic student movements as seen in late 1960s Japan - but it implies such behavior will be significantly more muted compared to socio-economically similar but independence-oriented cultural conditions.

These findings suggest that there is a general tendency for individuals to be more risk-averse than risk-taking in interdependent cultural contexts like Japan. It is therefore that much more difficult to overtly and one-sidedly push for structural and ideological adjustments in response to globalization pressures, especially when change pressures are perceived to threaten norms and practices of interdependence, social harmony, and adherence to hierarchy. On the societal level, "hot" reactions to globalization are therefore likely to persist under such socio-ecological conditions even if it comes at a high cost to economic growth and breeds economic insecurity for the middle-classes and young adults.

Since behavior is guided more by avoidance motivations and less by approach motivations in the Japanese cultural context, ritualism, and retreatism can be expected to be the default individuallevel responses whenever conformity - as a result of wide-scale socio-economic change, for example - becomes difficult to attain. On this point the sociological theory and psychological evidence that we have presented point in the same direction. However, it would clearly be incorrect to argue that the salience of avoidance motivations always leads to only ritualist or retreatist individuallevel adaptations in the face of globalization. We next turn to discuss an alternative type of adaptation. 


\section{"COOL" ADAPTATIONS BY TACTFUL YOUTH?}

Indeed, despite the presence of heavy cultural and institutional constraints, less conformist individuals do exist in Japan and some of them have found creative ways to negotiate life and work in globalizing society. In our Mertonian scheme, these nonconformists fall into the category of "mavericks" (Figure 2) that stands outside the framework of dominant cultural goals and institutionalized means. We hypothesize that, in the absence of large-scale revolution or new mass movements, they are the most likely group of young adults to actively shape social change, including more sustainable adaptations to globalization. This is because those who remain in one of the other adaptive categories (conformism, ritualism, and retreatism) lack the interest, skill and/or potential to re-configure the existing system as its beneficiaries, consumers, or outcasts. But what forms are maverick behavior likely to take in conformist, interdependence-oriented social and cultural contexts?

Famously, the most conspicuous maverick of 2000s Japan was Horie Takafumi, a talented Tokyo University graduate who came to be known for his aggressive trading practices, take-over bids and the Livedoor Incident (2006) that eventually led to a two-anda-half-year prison sentence for securities fraud, put into effect just as this article was being finalized in late June 2011. Horie's case is instructive because he had few qualms about challenging entrenched Japanese business interests, including those of the Japan Broadcasting Corporation and its elderly owners. His antics flew in the face of convention: by amassing a fortune by his late twenties, he challenged the seniority-based social model, and by attacking large conservative corporations, he exemplified the values of unbridled competition, individualism, and creativity. Horie in effect embodied the ethos of US-inspired global capitalism that was felt to be a threat by influential parts of the Japanese business world. Not surprisingly, he met with fierce resistance from the establishment, leaving some pundits believing that he was crushed by vested interests and punished disproportionately for the fraud he allegedly committed. While many young people looked to Horie as an iconic role model (Fackler, 2011), his defeat sent the depressing message to aspiring youth that it was simply not worth trying anything new in Japan's change-resistant enterprise environment.

Horie's misadventures highlight a critical dilemma faced by conformist societies: whenever their mainstream institutions and elites react to globalization in predominantly hot ways, cool and integrative adaptations by individuals and firms are resisted and held back by less adapted but powerful elements. This dynamic has, according to Schoppa (2006), possibly accelerated the mass exit from Japan of leading manufacturers, which could have been partly prevented via reasonable domestic reforms. Actors who develop new values and methods to cope in new conditions therefore find themselves in the tricky position of having to "resist the resistance" to globalization - or leave. But with the weight of mainstream society so formidable, open resistance can prove difficult to even highly skilled individuals (such as Horie).

This is partly why another quieter variety of young leaders in Japan has opted to negotiate conformist pressures in less explicit yet effective ways. Social entrepreneurs in various fields present a pertinent example here. These are highly ambitious, socially motivated individuals who lead flexible non-profit organizations and small for-profit companies. Kudo Kei, the well-connected manager of the brand-conscious youth work group Sodate-age Netto (Toivonen, 2009) and Komazaki (2007), the chief of the NPO Florence that provides temporary care to ill children, are two widely known cases in point. Importantly, instead of being openly confrontational with the state, local governments, and existing corporations, they seek to strategically engage such institutions, promoting their own unconventional ideas as "innovations" and "solutions" to social problems. Such young leaders (1) articulate original ideas and social visions; (2) employ original methods; (3) craft implicit strategies to challenge the status quo; (4) incorporate internationally diffused ideas (such as "self-efficacy" and "social inclusion"); and (5) fuse "Japanese" and "global" values (such as interdependence and independence $)^{12}$. These characteristics are consistent with our conception of quiet mavericks (Figure 2) as well as cool responses to globalization, offering us a snapshot of what more creative and integrative adaptations may look like in an intensely conformist society. With a growing number of Japanese-language publications on social entrepreneurship (see, e.g., Watanabe, 2005; Ooshima, 2009) and with elite youth beginning to view it as a dream occupation (interview with Kaneko Ikuta, June 27, 2011), we may soon witness a significant increase in quiet mavericks in Japan.

Of course, it is likely that such mavericks exist in a wide variety of domains, from online trading to art, fashion, and various for-profit businesses. Relevantly, existing research on entrepreneurship in Japan has noted that individual entrepreneurs, while in a position to exercise leadership, are far more group-oriented and far less aggressive in their behavior than their European or American counterparts (Richter, 2000, pp. 160-161; Miyamoto and Wilken, 2010). This seems to confirm our view that, if we are to look for change makers in advanced conformist societies, we should pay attention not only to examples like Horie but also to young adults who are less conspicuous yet highly tactful as they enact social change.

Assuming that youth can move between the four main categories set out in our schema of individual-level adaptations, where do quiet mavericks come from? Interestingly, it seems probable that they mainly comprise those who have first mastered the role of the conformist, for it is (ex-)conformists - not ritualists or retreatists - who possess the social capital (networks), psychological resources, and interpersonal skills that make it possible for them to strategically shift toward the role of a successful maverick. It makes sense also that such youth should possess postmaterialist values (see Inglehart and Welzel, 2005 again) as they have grown up in affluent conditions, and that they are the group that has the greatest potential to act on such values of openness, tolerance of diversity, and self-actualization. New empirical research is required to fully understand the characteristics and

\footnotetext{
${ }^{12}$ This is not to suggest that "successful" adaptation can never be critical toward the state, corporations, or global capitalism. Anti-capitalism activists, for example, resemble social entrepreneurs in that they too draw on internationally diffused ideas and discourses. However, activists usually need to be ready to deploy more confrontational tactics than "quiet mavericks," which means fewer youth in an interdependence-based culture are likely to join their ranks.
} 
strategies of such inconspicuous mavericks, but we believe it is this group that may drive the development of new working practices and alternative notions of successful careers in conformist, interdependence-oriented societies challenged by globalization.

\section{SUMMARY}

How have Japanese youth adapted their motivational processes and behaviors amid globalization-related cultural as well as institutional pressures? We began our analysis by noting how Japanese elites exhibited mainly "hot" reactions to globalization in the $1990 \mathrm{~s}$ and 2000s: they reformed the labor markets asymmetrically by protecting the core of the employment system, a dominant cultural symbol, while expanding the insecure peripheral labor force. Second, we found that those youth (ritualists) who were unable to become true conformists tended to remain in peripheral employment that rarely yields culturally expected rewards such as a stable income and good marriage prospects. We then focused specifically on those who move to retreatism as social withdrawees. Experimental data indicated that this group represents a deviation from central Japanese cultural values (interdependence), though without a clear movement toward Western motivational patterns (independence). This finding is interesting in light of a strong tendency to problematize and medicalize the hikikomori in Japan (see the excellent review by Horiguchi, 2011). Indeed, our data lends further support to the view that, rather than a pathology, withdrawal reflects the increasing marginalization of young people in the Japanese labor markets, leading to weaker socialization in terms of dominant Japanese work practices (but without compensatory socialization into alternative values or modes of action). Withdrawees can thus be viewed as the disempowered victims of the elites' hot reactions to globalization.

We furthermore offered a cultural psychological perspective for why avoidance motivations are so prevalent among Japanese youth. Consistent with our sociological analysis, this predicted that youth who cannot conform to standard life-course expectations (e.g., due to decreasing access to stable jobs) are likely to become ritualists or retreatists. Yet we also tentatively identified an actively non-conformist group (quiet mavericks). The features of this still insufficiently researched group hints at what "cool," or creative and integrative, adaptations to globalization may look like at the individual level in conformist societies. However, that "quiet mavericks" are required to be so agile, tactful, and culturally sensitive underscores the considerable difficulty of adapting well amid contradictory cultural pressures. It is clear that more research needs to be conducted to better understand the backgrounds, values, and trajectories of this group.

As our broad sociological frame, we relied on a four-fold Mertonian scheme that helps to illuminate particularly well the predicament of present-day Japanese youth: they are required to grapple with a growing gap between unchanging cultural goals and increasingly elusive institutional means. For the time being, this means-ends discrepancy remains acute, though once normative goals become too far-removed from lived realities - reaching a tipping point of sorts - it is likely that they will rapidly transform and diversify.

What are the implications of this account to globalizing conformist societies more generally? Perhaps the most obvious point is that, as social and economic change accelerates, conformist societies that are rigid and hierarchical may well fail an ever-larger segment of their youth. Clearly, the culturally defined goals and means that youth are required to conform to change too slowly to match the lived realities of young people who face shifting social structures. What makes swift adaptation particularly hard is the vast distance and oppositional relationship between global (independence-oriented) and local (interdependence-oriented) values. Less obviously, since most youth are encouraged to conform rather than to vocally air their grievances, there is only a weak push to reform values and institutions that no longer work for a significant minority (see Schoppa, 2006 on how a similar dynamic is affecting working women and large manufacturers). The demographic marginalization of young adults in the context of a radically aging society (Figure 1) may further weaken the force of reform pressures. Of course, a host of other variables may be relevant here, including the extent to which a country is oriented toward domestic rather than international markets, which is something that could be considered in future studies (especially those comparing Japan with South Korea and Taiwan).

Can these dilemmas be overcome? The pessimist might conclude that rapid globalization renders conformist societies and their interdependence-oriented cultural systems simply unviable. More optimistically, it may be possible to consciously promote "cool" - i.e., reflective and integrative - responses to globalization over "hot" ones among youth as well as decision-makers. This can be expected to be difficult where influential discourses (such as the Nihonjin-ron, or theories of Japaneseness, discourse in Japan) emphasize dichotomous distinctions between what is "foreign" - and hence negative - and what is "indigenous" - and hence superior. Yet public discourse can in theory frame differences not only in oppositional terms but positively as catalysts to creativity and synthesis. As Cheng and Chiu (2010) suggest in an earlier study on the psychological consequences of globalization, "when the situation emphasizes appropriating ideas from diverse cultures as intellectual forces to foster creative problem solving, simultaneous activation of cultural representations may facilitate the development of the expertise in creative conceptual expansion" (Chiu and Cheng, 2007). Although the issues highlighted by the analysis in this paper are highly complex and point to various policy implications, the success of conformist societies - including Japan's East Asian neighbors South Korea and Taiwan - that face intense globalization pressures may now hinge not on whether they can embrace global values in an uncritical sense, but on whether they can cultivate "cool" cultural and institutional adaptations among their citizenry and leaders.

\section{ACKNOWLEDGMENTS}

Tuukka Toivonen would like to warmly acknowledge the support he received from the Department of Sociology at Kyoto University and the Japan Society for the Promotion of Science in 2009-2010. All authors thank the Kokoro Research Center and the Global Center of Excellence program on the Reconstruction of the Intimate and Public Spheres for sponsoring a special workshop on youth problems in Kyoto in June 2010. 


\section{REFERENCES}

Arnett, J. J. (2004). Emerging Adulthood: The Winding Road From the Late Teens Through the Twenties. Oxford: Oxford University Press.

Brinton, M. (2011). Lost in Transition: Youth, Work, and Instability in Postindustrial Japan. Cambridge: Cambridge University Press.

Cabinet Office. (2007). Kokumin Seikatsu ni Kansuru Yoron-chousa (A Survey on the Life of the Nation). Tokyo: Cabinet Office of Japan.

Cheng, S. Y. Y., and Chiu, C.-Y. (2010). "Cultural psychology of globalization," in Personality, Human Development, and Culture: International Perspectives on Psychological Science, Vol. 2, eds. R. Schwarzer and P. A. French (New York: Psychology Press), 199-212.

Chiavacci, D. (2008). From class struggle to general middle-class society to divided society: societal models of inequality in postwar Japan. Soc. Sci. Jpn. J. 11, 5-27.

Chiu, C.-Y., and Cheng, S. Y. (2007). Toward a social psychology of culture and globalization: some social cognitive consequences of activating two cultures simultaneously. Soc. Pers. Psychol. Compass 1, 84-100.

Elliot, A. J. (1999). Approach and avoidance motivation and achievement goals. Educ. Psychol. 34, 149-169.

Fackler, M. (2011). In Japan, Young Face Generational Roadblocks. The New York Times, January 28.

Geertz, C. (1984). "From the native's point of view," in Culture Theory, eds. R. A. Shweder and R. A. Levine (Cambridge: Cambridge University Press), 126.

Genda, Y. (2005). A Nagging Sense of Job Insecurity: The New Reality Facing Japanese Youth. Tokyo: International House Press.

Goodman, R., Imoto, Y., and Toivonen, T. (eds). (2011). A Sociology of Japanese Youth: From Returnees to NEETs. Abingdon: Routledge.

Gottfried, H. (2008). Pathways to economic security: gender and nonstandard employment in contemporary. Soc. Indic. Res. 88, 179-196.

Hall, P. A., and Gingerich, D. W. (2009). Varieties of capitalism and institutional complementarities in the political economy: an empirical analysis. Br. J. Polit. Sci. 39, 449-482.

Hamamura, T., Meijer, Z., Heine, S. J., Kamaya, K., and Hori, I. (2009). Approach-avoidance motivations and information processing: a cross-cultural analysis. Pers. Soc. Psychol. Bull. 35, 454-462.

Heine, S. J., Kitayama, S., Lehmand, D. R., Takata, T., Ide, E., Leung, C., and Matsumoto, H. (2001). Divergent consesequences of success and failure in Japan and North America. An investigation of self-improving motivations and malleable selves. $J$. Pers. Soc. Psychol. 81, 599-615.

Heine, S. J., Lehmand, R., Markus, H. R., and Kitayama, S. (1999). Is there a universal need for positive selfregard? Psychol. Rev. 106, 766-794.

Henrich, J., Heine, S. J., and Norenzayan, A. (2010). The weirdest people in the world? Behav. Brain Sci. 33, 61-83.

Higgins, E. T. (1997). Beyond pleasure and pain. Am. Psychol. 52, 1280-1300.

Horiguchi, S. (2011). "Hikikomori: how private isolation caught the public eye," in A Sociology of Japanese Youth: From Returnees to NEETs, eds. R. Goodman, Y. Imoto, and T. Toivonen (Abingdon: Routledge), 122-138.

Inglehart, R., and Welzel, C. (2005). Modernization, Cultural Change, and Democracy. Cambridge: Cambridge University Press.

Kariya, T. (2011). Credential inflation and employment in "universal" higher education: Enrolment, expansion, and (in)equity via privatisation in Japan. J. Educ. Work 24, 69-94.

Kariya, T., and Rosenbaum, J. (2003). "Stratified incentives and life course behaviors," in Handbook of the Life Course, eds. J. Mortimer and M. Shanahan (New York: Springer), 51-78.

Kitayama, S., Markus, H. R., Matsumoto, H., and Norasakkunkit, V. (1997). Individual and collective processes in the construction of the self: self-enhancement in the United States and self-criticism in Japan. J. Pers. Soc. Psychol. 72, 1245-1267.

Kitayama, S., and Uchida, Y. (2003). When implicit and explicit selfevaluations fail to converge: evaluating self and friend in two cultures. J. Exp. Soc. Psychol. 39, 476-482.

Komazaki,H. (2007). "Shakai wo Kaeru" wo Shigoto ni Suru Shakai Kigyouka to Iu Ikikata (The Life-Style of Social Entrepreneurs whose Work is to "Change Society"). Tokyo: Eiji Shuppan.

Kosugi, R. (2008). Escape From Work: Freelancing Youth and the Challenge to Corporate Japan. Melbourne: Trans Pacific Press.

Markus, H. R., and Kitayama, S. (1991). Culture and the self: implications for cognition, emotion, and motivation. Psychol. Rev. 98, 224-253.

Merton, R. K. (1938). Social structure and anomie. Am. Sociol. Rev. 3 672-682.

Merton, R. K. (1949). Social Theory and Social Structure. New York: Free Press.

Mills, M., and Blossfeld, H.-P. (2005). "Globalization, uncertainty and the early life-course: a theoretical framework," in Globalization, Uncertainty and Youth in Society, eds. H.-P. Blossfeld, E. Klijzing, M. Mills, and K. Kurz (Abingdon: Routledge), $1-24$.

Ministry of Education. (2010). Gakkou Kihon Chousa (The Basic School Survey). Tokyo: Ministry of Education, the Government of Japan. Available at: http://www.mext.go.jp/ b_menu/toukei/chousa01/kihon/126 7995.htm [accessed May, 3 2011].

Miyamoto, Y., and Wilken, B. (2010). Culturally contingent situated cognition: influencing others fosters analytic perception in the U.S. but not in Japan. Psychol. Sci. 21, 16161622.

Morling, B., Kitayama, S., and Miyamoto, Y. (2002). Cultural practices emphasize influence in the United States and adjustment in Japan. Pers. Soc. Psychol. Bull. 28 311-323.

Nakane, C. (1970). Japanese Society. Berkeley: University of California Press.

Norasakkunkit, V., and Uchida, Y. (in press). Psychological consequences of post-industrial anomie on self and motivation among Japanese youth. J. Soc. Issues.

Ooshima, N. (2009). Shakai Kigyouka ni Naru Houhou (How to Become a Social Entrepreneur). Tokyo: Aspect.

Pilkington, H., and Johnson, R. (2003). Relations of identity and power in global/local context. Cult. Stud. 6 , 259-283.

Rebick, M. (2005). The Japanese Employment System: Adapting to a New Economic Environment. Oxford: Oxford University Press.

Richter, F.-J. (2000). Strategic Networks: The Art of Japanese Interfirm Cooperation. New York, NY: International Business Press.

Schoppa, L. (2006). Race for the Exits: The Unraveling of Japan's System of Social Protection. Ithaca, NY: Cornell University Press.

Shirahase, S. (2009). "Marriage as an association of social classes in a low fertility rate society: towards a new theory of social stratification," in Social Class in Contemporary Japan: Structures, Sorting and Strategies, eds. H. Ishida and D. Slater (Abingdon: Routledge), 57-84.

Statistics Bureau. (2011). Labor Force Survey (Long-Term Time Series Data). Tokyo: Ministry of Internal Affairs and Communications, the Government of Japan. Available at: http://www.e-stat.go.jp/SG1/estat/ List.do?bid $=000001007702 \&$ cycode $=0($ accessed May 52011$)$.

Toivonen, T. (2009). Explaining Social Inclusion and Activation Policy for Youth in 21st Century Japan. Ph.D. Thesis, University of Oxford, Oxford.

Toivonen, T., and Imoto, Y. (2011) "Making Sense of Youth Problems," in A Sociology of Japanese Youth: From Returnees to NEETs, eds. R. Goodman, Y. Imoto, and T. Toivonen (Abingdon: Routledge), $1-29$.

Uchida, Y., Norasakkunkit, V., Kishimoto, S., Fujiwara, M., Kondo, M. and Morisaki, S. (2010). Seinenki no shyakaiteki tekiyou: hikikomori/NEET to no bunka shinrigakuteki kentou (How adolescents can adjust to society: considerations from a cultural psychological perspective). Poster presented at the Annual Research Report Conference of the Kokoro Research Center (Kyoto: Kyoto University).

Watanabe, N. (2005). Chenji Meekaa: Shakai Kigyouka ga Yo no Naka wo Kaeru (Change Makers: Social Entrepreneurs Will Change the World). Tokyo: Nikkei BP-Sha.

Weathers, C. (2001). Changing white collar workplaces and female temporary workers in Japan. Soc. Sci. Jpn. J. 4, 201-218.

Yamada, M. (2011). "The young and the hopeless," in Reimagining Japan: The Quest for a Future that Works, ed. McKinsey and Company (San Francisco: VIZ Media), 176-180.

Zielenziger, M. (2006). Shutting Out the Sun: How Japan Created Its Own Lost Generation. New York: Nan A. Talese.

Conflict of Interest Statement: The authors declare that the research was conducted in the absence of any commercial or financial relationships that could be construed as a potential conflict of interest.

Received: 21 June 2011; paper pending published: 04 July 2011; accepted: 13 August 2011; published online: 13 September 2011.

Citation: Toivonen T, Norasakkunkit V and Uchida Y (2011) Unable to conform, unwilling to rebel? Youth, culture, and motivation in globalizing Japan. Front. Psychology 2:207. doi: 10.3389/fpsyg.2011.00207

This article was submitted to Frontiers in Cultural Psychology, a specialty of Frontiers in Psychology.

Copyright (C) 2011 Toivonen, Norasakkunkit and Uchida. This is an open-access article subject to a nonexclusive license between the authors and Frontiers Media SA, which permits use, distribution and reproduction in other forums, provided the original authors and source are credited and other Frontiers conditions are complied with. 